\title{
Coincidental changes in conscious level and lens translucency during treatment of diabetic ketoacidosis
}

\author{
R. J. M. GORRALL \\ Diabetic Out-Patients Department, Royal Infirmary, Edinburgh
}

During conventional treatment of diabetic ketoacidosis deterioration in the patient's conscious state may occur. This may be temporary or death may result; cerebral oedema has been the striking finding post mortem (Dillon, Riggs, and Dyer, 1967 ; Fitzgerald, O'Sullivan, and Malins, I96ı ; Young and Bradley, 1967). Temporary cataracts have been described in newly diagnosed diabetics during the early days of treatment (Lawrence, 1946; Jackson, 1955). In the present communication a patient is described in whom deterioration in conscious state and temporary cataract were associated; a common pathogenesis is suggested.

\section{Case report}

A 56-year-old female with diabetes of 2 years' duration, previously controlled on insulin zinc suspension (lente), 32 units daily, was admitted as an emergency on July 15,1970 at 20.00 hrs. She was drowsy and could not give a clear history. Later it was learned that she had not taken insulin for the previous 3 days. The clinical features were those of diabetic ketoacidosis. Fig. I records the biochemical data and treatment.

In the first 2 hrs of therapy her conscious level deteriorated rapidly and next morning she was unresponsive to maximal stimulation. There was no improvement until the following day (July 17 ) when she showed some response to stimulation, and by the morning of July 18 she was answering simple questions. Thenceforth she made a gradual recovery and was discharged home ambulant on September 8, 1970.

On admission the fundi were clearly visible, but the following morning the lenses were totally opaque. In spite of full mydriasis no red reflex could be seen throughout the next 2 days but on the morning of July 18 the fundi could once again be examined without difficulty.

Address for reprints: R. J. M. Corrall, M.R.C.P., Diabetic OutPatients Department, Royal Infirmary, Edinburgh EH3 9YW

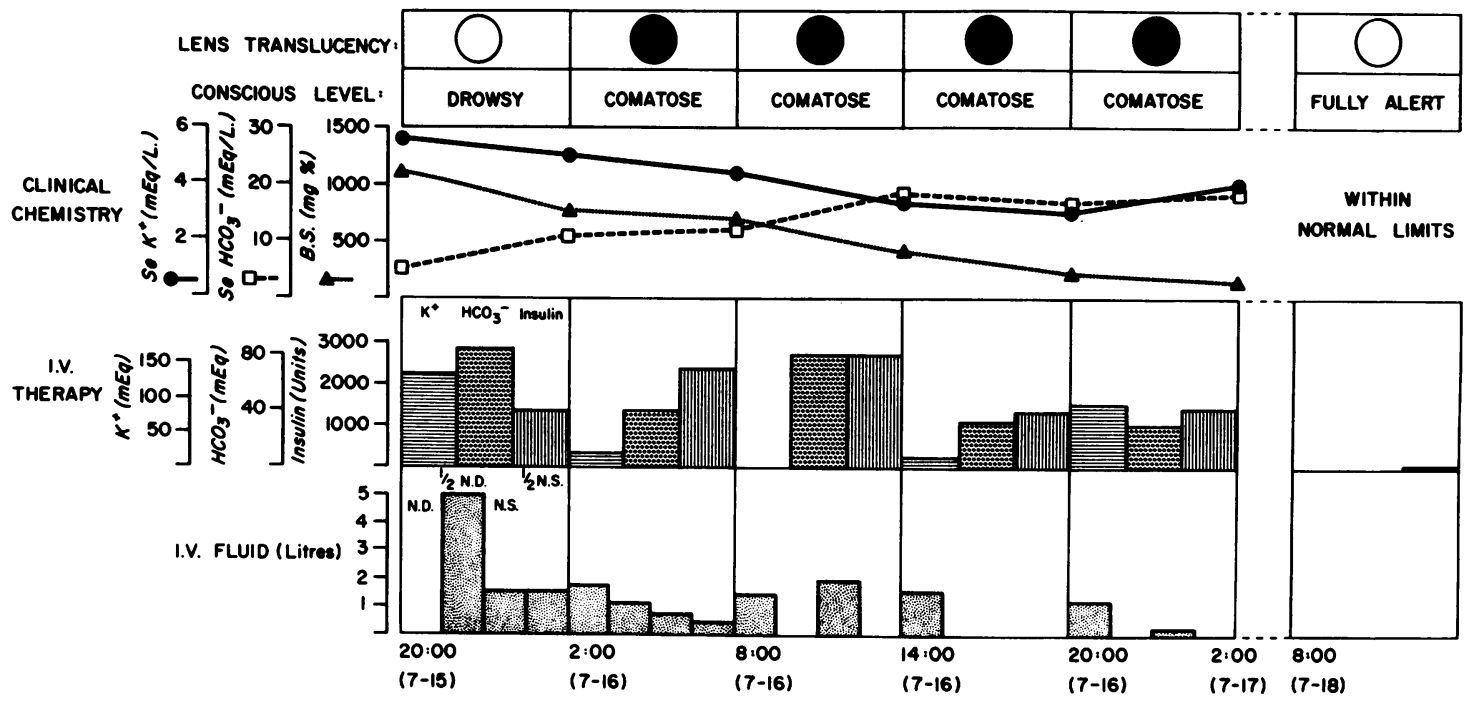

FIG. I Sequential biochemical data at 6-hrly intervals from admission. From 20.00 hrs on Fuly 17, I970, the biochemical state remains within normal limits 


\section{Discussion}

The main interest in the present case accrues from the coincidental changes in cerebral state and lens translucency. It is unlikely that the lens changes were due to dehydration as may occur in cholera (Manson-Bahr, 1946), since the opacity was absent before starting intravenous therapy and persisted long after rehydration had been achieved. It is also unlikely that the deterioration in consciousness was due to cerebrospinal fluid acidosis induced by rapid bicarbonate administration (Posner and Plum, 1967), since deterioration occurred before any bicarbonate had been given and the bicarbonate was infused slowly.

Lawrence (1946) described two instances of temporary cataract in diabetics that followed 16 and 3 days after therapeutic reduction of blood sugar. He suggested that cataracts might be due to rehydration under treatment. Jackson (1955) added a similar case and questioned the importance of hydration. Intracellular sorbitol accumulation in the lens has been postulated as the cause of metabolic cataract in diabetics (Van Heyningen, 1962; Pirie and Van Heyningen, 1964; Kinoshita, Merola, and Hayman, I965). Sorbitol is formed within the lens in the presence of a rise in glucose concentration of the aqueous humour (due to hyperglycaemia) under the influence of aldose reductase (see Fig. 2). The ability of the normal lens to concentrate amino-acids is impaired by incubation in a medium of high glucose or galactose concentration. Furthermore this is associated with intralenticular accumulation of the corresponding polyols and of water. Kinoshita and others (1965) have shown that this impairment may be prevented by an external medium of high sorbitol concentration. This work provides strong evidence that the harmful effects of intralenticular sorbitol accumulation is mediated by an osmotic mechanism. It is tempting to explain the temporary cataracts on a similar basis, their precipitation with treatment being due to accentuation of osmotic gradients.

Clements, Prockop, and Winegrad (1968) have proposed a model to explain the occurrence of cerebral oedema during the treatment of diabetic ketoacidosis. Dogs which were exposed to hyperglycaemia for $4 \mathrm{hrs}$ and then to a similar period of rehydration with isotonic saline developed an increased cerebrospinal fluid pressure due to cerebral oedema. Furthermore this was associated with raised cerebrospinal fluid levels of fructose and sorbitol. The cause of this cerebral oedema is thus thought to be an osmotic gradient resulting from intracellular sorbitol accumulation and a fall in blood osmolality due to specific treatment. More recently, Clements, Blumenthal, Morrison, and Winegrad (197I) have demonstrated that treatment of diabetic ketosis resulted in a rise in cerebrospinal fluid pressure in five patients. Though not giving direct evidence for the sorbitol hypothesis, this does indicate that transient cerebral oedema may occur during treatment and is compatible with complete recovery.

The author suggests that unconsciousness and cataract in the present case were precipitated by oedema of the brain and of the lens resulting from the osmotic effect of a high intracellular concentration of sorbitol and a sudden fall in extracellular osmolality due to treatment. The unifying fact of the two tissues would appear to be their permeability to glucose in the absence of insulin Pohjolas, 1966; Giles and Harris, 1959).

This explains their intracellular accumulation

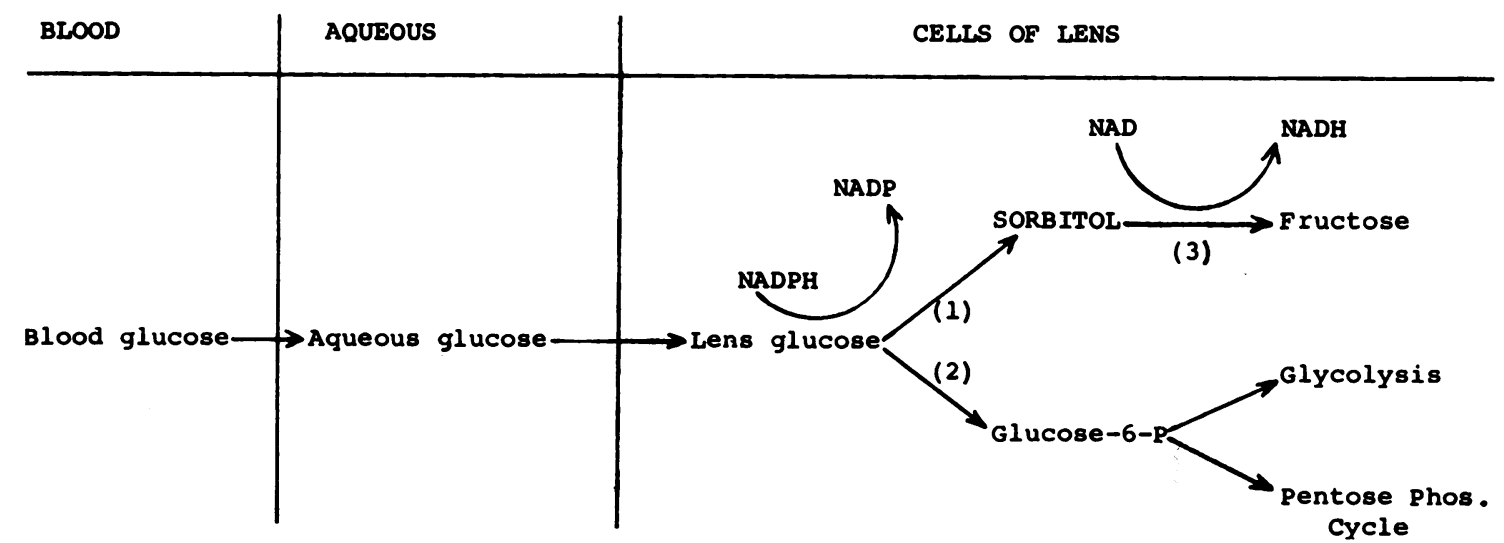

FIG. 2 The sorbitol pathway. Glucose concentration of aqueous relates closely to blood level, but in the lens is normally Io per cent. of this. In the presence of hyperglycaemia the increased load of glucose to the lens is mainly dealt with by Reaction I (catalysed by aldose reductase) rather than Reaction 2 (hexokinase enzyme) which is already operating at maximum efficiency. This results in the intracellular accumulation of sorbitol. The cells are impermeable to sorbitol and its removal is therefore solely dependent on its metabolism by polyol dehydrogenase to fructose (Reaction 3). 
of glucose with hyperglycaemia and the resultant activation of the sorbitol pathway.

\section{Summary}

A case of diabetic ketoacidosis treated by the usual methods is described. With correction of the bio- chemical abnormalities in the plasma the patient's conscious state deteriorated and loss of lens translucency occurred. The patient's conscious state recovered after more than 2 days and this was accompanied by a return of normal lens translucency. A common pathogenesis involving the sorbitol pathway is postulated.

\section{References}

CLEMENTS, R. S., BLUMENThAL, S. A., MORRISON, A. D., and WinEGRAD, A. I. (I97I) Lancet, 2, 67I -, PROCKOP, L. D., and WINEGRAD, A. I. (1968) Ibid., 2, 384

DILlon, E. S., RIGGS, H. E., and DYER, W. W. (1936) Amer. F. med. Sci., 192, 360

FitzGerald, M. G., o'sullivan, D. J., and malins, J. M. (I96I) Brit. med. F., I, 247

GILES, K. M., and HARRIS, J. E. (1959) Amer. F. Ophthal., 48, 508s

JACKSON, R. C. (1955) Brit. F. Ophthal., 39, 629

kinoshita, J. H., MERola, L. o., and hayman, s. (1965) F. biol. Chem., 240, 3 Io

LAWRENCE, R. D. (1946) Brit. F. Ophthal., 30, 78

MANSON-BAHR, P. (1946) 'Manson's Tropical Diseases", i 2th ed., p. 456. Cassell, London

PIRIe, A., and VAN HEYNingen, R. (1964) Exp. Eye Res., 3, 124

POHJOLAs, I. (I966) Acta ophthal. (Kbh.), Suppl. 88, p. 5 I

POSNER, J. B., and Plum, F. (1967) New Engl. J. Med., 277, $60_{5}$

VAN HeYNingen, R. (1962) Exp. Eye Res., I, 396

Young, E., and BRADLEY, R. F. (1967) New Engl. F. Med., 276, 665 